\title{
Antimicrobial activity of extract of different quality strawberry against antibiotic-resistant Staphylococcus aureus
}

\section{$\mathrm{UCEMICH}$}

\footnotetext{
${ }^{1}$ Instituto Politécnico Nacional, Centro Interdisciplinario de Investigación para el Desarrollo Integral Regional Unidad Michoacán. Justo Sierra Ote. 28 , Col. Centro, C.P. 59510, Jiquilpan, Michoacán, MX.

${ }^{2}$ Universidad de la Ciénega del Estado de Michoacán de Ocampo, Av. Universidad 3000, Col. Lomas de Universidad, C.P. 59103, Sahuayo, Michoacán, MX.
}

*Corresponding author, email: jcardenasv@ipn.mx

\section{Introduction}

Inflammation of the mammary gland in cattle is known as mastitis, it is one of the most prevalent and expensive diseases of dairy herds worldwide, and antibiotic therapy is the main tool for its treatment (Hogeveen et al., 2011 ). Staphylococcus aureus is responsible for most cases of subclinical mastitis in dairy cows (Mestorino and Errecalde, 2012). This microorganism is characterized by the ability to develop resistance against various traditional antimicrobials, which represents a serious problem in the dairy production chain (Basanisi et al., 2017). Therefore, research for the development of new drugs that fight this disease is of utmost importance. Plants are promising sources of new biological agents with antibacterial action, in addition to having the advantage of not inducing resistance even after prolonged exposure (Gomes et al., 2016; Domadia et al., 2007). Strawberry (Fragaria $x$ ananassa) is a berry with an important amount of metabolites, mainly anthocyanins, phenolic compounds and flavonoids (Basu et al., 2016; Aaby et al., 2007; Giamperi et al., 2012); The beneficial potential that these compounds present in strawberry fruit have on human, animal and plant health has been demonstrated (Giamperi et al., 2015; Giamperi et al., 2013; Nohynek, et al., 2006; Puuponnen et al ., 2001). However, the strawberry is a nonclimacteric fruit, with a short shelf life, so much of what is harvested that does not meet the characteristics of export quality (Extra quality), is destined for the national fresh market (first quality ), to industrialization (first and / or second quality) or to waste. In this sense, the objective of this work was to evaluate the antimicrobial activity of 3 quality strawberry fruits against multidrug-resistant $\mathrm{S}$. aureus caused by bovine mastitis, as a proposal for a viable alternative to add value to the strawberry that does not reach quality of export (first and second quality).

\section{Materials and methods}

Biological material

The multi-resistant strains of $S$. aureus AMC $9^{*}$ and AMC $23^{* *}$ were isolated from milk samples from cows with mastitis in the Ciénega de Chapala region, Michoacán, Mexico, and strain ATCC 27543 as reference. For the extraction of anthocyanins, strawberry fruits (F. $x$ ananassa) of export quality (MEX Extra) (Driscoll's $s^{\circledR}$ ), first quality (MEX1) and second quality (MEX2) purchased at the local market of Sahuayo, Michoacán were used. The fruits were lyophilized and stored in a dark desiccator at room temperature $\left(23 \pm 5^{\circ} \mathrm{C}\right)$ until processing.

*AMC 9: Resistant to ampicillin, cephalothin, cefotaxime, cefuroxime, dicloxacillin, erythromycin, cefepime, gentamicin, penicillin.

**AMC 23: Resistant to ampicillin, cefotaxime, cefuroxime, erythromycin, cefepime, penicillin, trimethoprim-sulfamethoxazole, tetracycline.

\section{Anthocyanin extraction from strawberry fruits}

The technique described by Abdel-Aal and Hucl (1999) was used, which consisted of taking $1 \mathrm{~g}$ of sample and $5 \mathrm{~mL}$ of acidified ethanol (ethanol and $1 \mathrm{~N} \mathrm{HCl} ; 85: 15 \mathrm{v} / \mathrm{v}$ ) and It was macerated in a mortar. Subsequently, the solutions were vigorously stirred in Vortex and the $\mathrm{pH}$ was adjusted to 1 with $1 \mathrm{~N}$ hydrochloric acid. Then, the solutions were stirred (LSE ${ }^{\circledR}$ orbital shaker) at $250 \mathrm{rpm}$ for $16 \mathrm{~h}$, at room temperature. After the time, the solutions were centrifuged at 6,000 rpm for $15 \mathrm{~min}$ and the supernatant was recovered, which was titrated to $25 \mathrm{~mL}$ with acidified ethanol. The concentration of cyanidine 3glycoside (Cy3G) was determined by colorimetry according to the technique described by the author. The samples were stored at $-20^{\circ} \mathrm{C}$ until use.

Minimum Inhibitory Concentration (MIC) and Bactericidal (MBC)

The MIC of the total extracts was determined for the pathogenic strains evaluated, using the microdilution method with some modifications (Seleshe et al., 2017). In 96-well microplates with $100 \mu l$ of Mueller-Hinton broth (Sigma-Aldrich ${ }^{\oplus}$ ), $20 \mu \mathrm{l}$ of bacterial inoculum adjusted to $10^{8} \mathrm{CFU} \mathrm{ml}^{-1}$ was

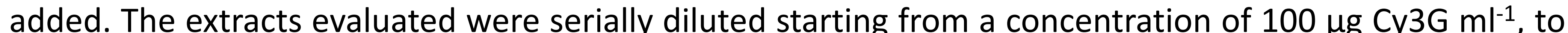
obtain 10 dilutions $\left(100,50,25,12.5,6.3,3.2,1.5,0.8,0.4\right.$ and $\left.0.2 \mu \mathrm{g} \mathrm{ml}^{-1}\right)$ and 50 were added $\mu \mathrm{l}$ to each well, respectively. The microplates were incubated at $37^{\circ} \mathrm{C}$ with constant agitation at $150 \mathrm{rpm}$ for $16-18$ h. Sterility control (Mueller-Hinton broth), growth control (broth + inoculum) and antibiotic control (Trimethoprim-Sulfamethoxazol ${ }^{\oplus}, 10 \mu \mathrm{g} / \mathrm{ml}$ ) were included. After incubation, the turbidity of the samples was measured to determine the MIC by spectrophotometry (BioTek PowerWave HT, USA). Additionally $10 \mu \mathrm{l}$ of aqueous tetrazolium bromide solution (MTT) (3- (4,5-dimethylthiazol-2-yl)-2,5diphenyltetrazolium bromide, $1 \mathrm{mg} \mathrm{m}^{-1}$, Sigma-Aldrich ${ }^{\circledR}$ ) was added to the wells as a growth indicator and then incubated for $2 \mathrm{~h}$. The color change to blue-purple indicates bacterial growth. The lowest concentration of the wells without coloration was considered the minimum inhibitory concentration. For the determination of the MBC, $100 \mu$ l of each well without color change was plated on Mueller-Hinton agar (Sigma-Aldrich ${ }^{\circ}$ ) and incubated at $37^{\circ} \mathrm{C}$ for 24 hours. The lowest concentration that did not produce growth after this subculture was considered the CMB. All trials were carried out in triplicate.

\section{Statistical analysis}

Each experiment was carried out in triplicate. An analysis of variance and the comparison of Tukey means was performed using the SAS statistical software (version 9.0, Cary, NC, USA) and a difference of $p<0.05$ was considered significant.

\section{Results and Discussion}

The concentration of cyanidine 3-glycoside (mg eq $100 \mathrm{~g}^{-1}$ fresh fruit (ff)) of the anthocyanin extracts of strawberry fruits of 3 qualities was determined, the results are shown in Table 1 . The differences in the concentration of anthocyanins in the quality of the fruit evaluated are significant, being the first quality strawberry extract (MEX1) which had the highest concentration of the cyanidin 3-glucoside anthocyanin pigment, followed by the second quality fruits (MEX2) and finally the extra quality fruits (MEX Extra). The concentrations shown by the strawberry fruits evaluated agree with Karaaslan and Yaman (2017), which obtained values of $40.2 \pm 0.5 \mathrm{mg}$ cyanidine 3-glycoside $100 \mathrm{~g}^{-1}$. Likewise, the results are consistent with those reported by the USDA (2019), with values up to $22 \mathrm{mg}$ Cy3G $100 \mathrm{~g}^{-1}$.
These differences in the amount of anthocyanins between strawberry fruit quality evaluated can be explained by the degree of ripeness of the fruit at the time of processing. According to Williner (2003), the highest anthocyanin content is observed in fully ripe strawberry fruits, while some phenolic compounds such as ellagic acid decrease their concentration.

Table 1. Cyanidine 3-glycoside ( $\left.\mathrm{mg} 100 \mathrm{~g}^{-1}\right)$ concentration of anthocyanin of strawberry fruit extracts of 3 different quality.

\begin{tabular}{|c|c|}
\hline Strawberry fruit quality & $\begin{array}{l}\text { Cyanidine 3-glycoside concentration (mg } \\
100 \mathrm{~g}^{-1} \text { ) }\end{array}$ \\
\hline MEX Extra & $23.7 \pm 1.28 \quad \mathrm{c}$ \\
\hline MEX 1 & $43.9 \pm 0.5 \quad$ a \\
\hline MEX 2 & $31.1 \pm 0.53 \quad b$ \\
\hline
\end{tabular}

The values indicate the average of 3 replicas \pm standard
significant differences between treatments $(n=3, p \leq 0.05)$

The 3 types of strawberry showed an obvious inhibitory potential against all the pathogens evaluated (MIC, Table 2). Anthocyanin extracts of second quality strawberry fruits (MEX2) showed greater inhibitory capacity against all strains (6.3 to $12.5 \mathrm{\mu g} \mathrm{ml}^{-1}$ ) compared to extra and first quality fruits (MEX Extra and MEX1), in which the MIC was $25 \mathrm{\mu g} \mathrm{ml}^{-1}$ for all strains, with the exception of the reference strain ATCC 27543, which obtained inhibition at a concentration of $12.5 \mathrm{\mu g} \mathrm{ml}^{-1}$ of the first quality strawberry extract (MEX1). Regarding the Minimum Bactericidal Concentrations (MBC) (Table 2) the results showed differences between the 3 qualities of fruits compared to the strains evaluated. Again, all the strains evaluated were more susceptible to second quality or waste strawberry extract (MEX2) with CMB values of $25 \mathrm{\mu g} \mathrm{m}^{-1}$, followed by extra quality strawberry extract (MEX Extra) with values of $50 \mu \mathrm{g}$ $\mathrm{ml}^{-1}$; and, finally, the strawberry extract of first quality (MEX1), which obtained CMB of $100 \mathrm{mg} \mathrm{ml}^{-1}$ with the exception of the multi-resistant strain AMC 23, with CMB value of $50 \mu \mathrm{g} \mathrm{ml}^{-1}$.

Table 2. Minimal Inhibitory Concentrations (MIC) and Minimal Bactericidal Concentrations (MBC) of strawberry fruit extracts of 3 different quality against multiresistant $S$. aureus bovine mastitis isolates.

\begin{tabular}{cccccccc}
\hline \multirow{2}{*}{ Strain } & \multicolumn{7}{c}{ Strawberry fruit quality } \\
\cline { 2 - 8 } & MEX Extra & MEX 1 & MEX 2 & \\
\hline \multirow{2}{*}{ ATCC 27543 } & MIC & $25 \pm 0.52$ & b & $12.5 \pm 0.52$ & a & $12.5 \pm 0.41$ & a \\
& MBC & 50 & & 100 & & 25 & \\
\multirow{2}{*}{ AMC 9 } & MIC & $25 \pm 0.41$ & b & $25 \pm 0.52$ & b & $6.3 \pm 0.55$ & a \\
& MBC & 50 & & 100 & & 25 & \\
\multirow{2}{*}{ AMC 23 } & MIC & $25 \pm 0.98$ & b & $25 \pm 1.05$ & b & $12.5 \pm 0.75$ & a \\
& MBC & 50 & & 50 & & 25 & \\
\hline
\end{tabular}

indicate significant differences between treatments $(n=3, p \leq 0.05)$.

Anthocyanins have also been the focus of various investigations, mainly for their antioxidant activity (Viskelis et al., 2009; Giamperi et al., 2012; Lila, 2004). However, the antimicrobial activity of anthocyanin pigments present in various fruits, flowers and plants has gained vital interest in the search for antibacterial compounds. Pertuzzatti et al. (2016) observed the potential antimicrobial activity of cranberry extracts (Vaccinium ashei) from different cultivars against $\mathrm{E}$. coli (WCC, 20-35 mg ml-1; CMB, $30-45 \mathrm{mg} \mathrm{ml}-1$ ) and attribute to the anthocyanins found (cyanidine, petunidine, malvidin and delfinidine, in its glycosylated form) this action. They attribute this fact to the partial hydrophobicity of the phenolic compounds and anthocyanins present, which allow destabilizing the cell wall of lipopolysaccharides in the case of Gram (-) bacteria. Hafidh et al. (2011) found antimicrobial activity of anthocyanin extracts of red cabbage (Brassica oleraesea) against clinical isolates of methicillin-resistant $\mathrm{S}$. aureus (MRSA) with MIC values 10 to 40 times higher than those found in the present investigation. The author mentions that the mixture of phenolic compounds present in extracts of purple cabbage has high antioxidant activity, which acts as a protective agent for cells. This synergistic effect of the phenolic compounds, in particular of the mixture of anthocyanins present, can explain the antimicrobial potential, suggesting as a mechanism of action the alteration in cell permeability, causing deformation in its structure and damage in functionality.

\section{Conclusions}

The multiresistant strains of $\mathrm{S}$. aureus that cause bovine mastitis are susceptible to strawberry anthocyanin extracts, in addition to a quality-dependent effect of the fruit evaluated, the second quality strawberry fruit extract (MEX2) being observed. which has greater inhibitory and bactericidal activity.

\section{References}

Gomes, F., and Henriques, M. (2016). Current Microbiology, 72(4), 377-382.

Basu, A., Nguyen, A., Betts, N., Lyons, T. J. (2016). Critical Reviews in Food Science and Nutrition, 54(6), 790-806 Puupponen-Pimia, R., Nohynek, L., Meier, C., Kahkonen, M., Heinonen, M., Hopia, A., Oksman-Caldentey, K.-M. (2001). Journal of Applied Microbiology, 90(4), 494-507.

Karaaslan, N., Yaman, M. (2018). International Journal of Food Properties, 20(3), S2313-S2322.

Williner, R., Pirovani, E., Guemes, R. (2003). Journal of the Science of Food and Agriculture. 83:842-845.

Pertuzatti, P., Barcia, M., Rebello, L., Gómez-Alonso, S., Duarte, R., Duarte, M., Hermosín-Gutiérrez, I. (2016). Journal of Functional Foods, 26, 506-516. 